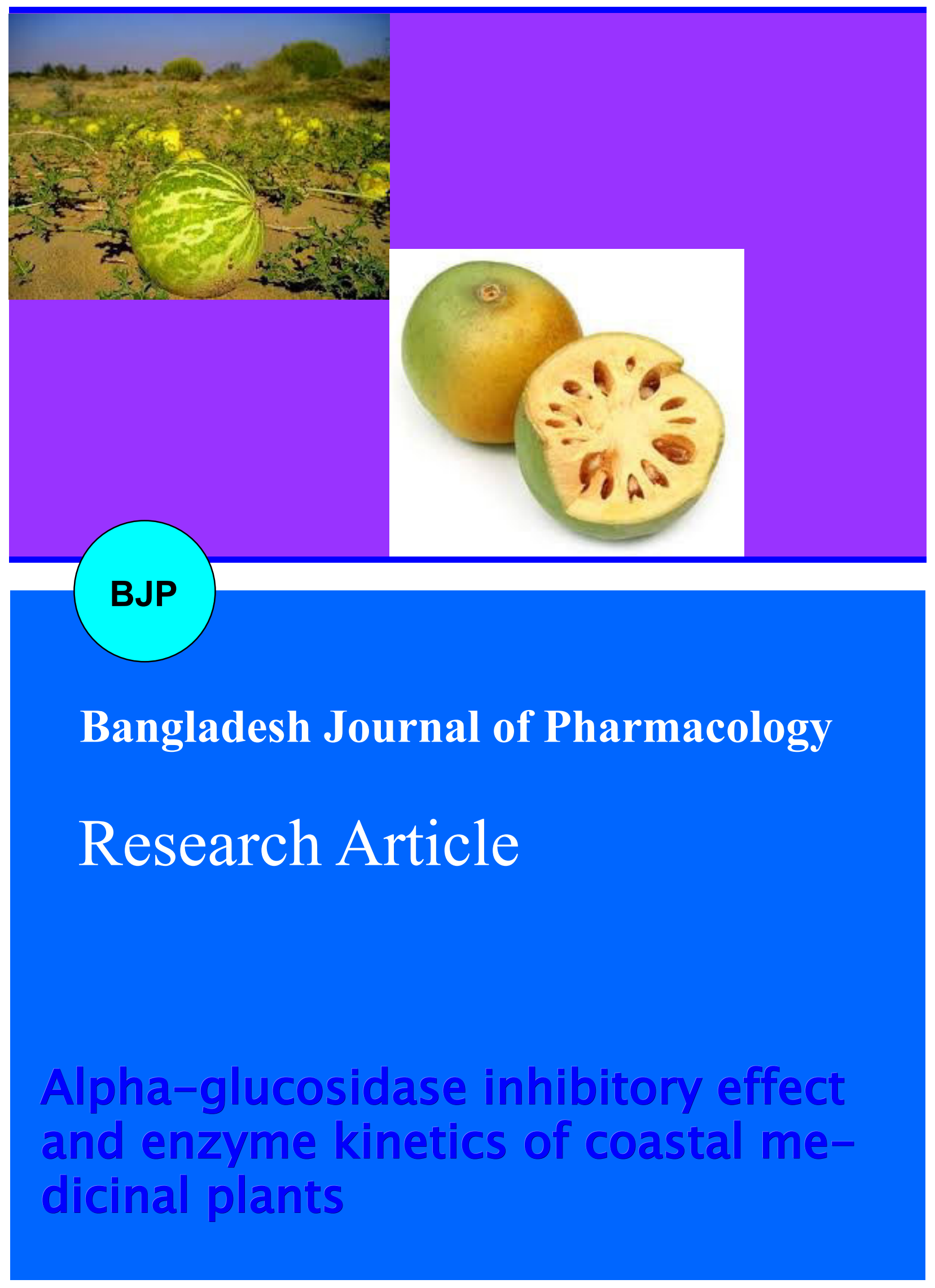




\title{
Alpha-glucosidase inhibitory effect and enzyme kinetics of coastal medicinal plants
}

\author{
Selvaraj Gurudeeban, Kaliyamurthi Satyavani and Thirugnanasambandam Ramanathan
}

Marine Medicinal Plant Biotechnology Division, Centre of Advanced Study in Marine Biology, Faculty of Marine Sciences, Annamalai University, Parangipettai 608502, Tamil Nadu, India.

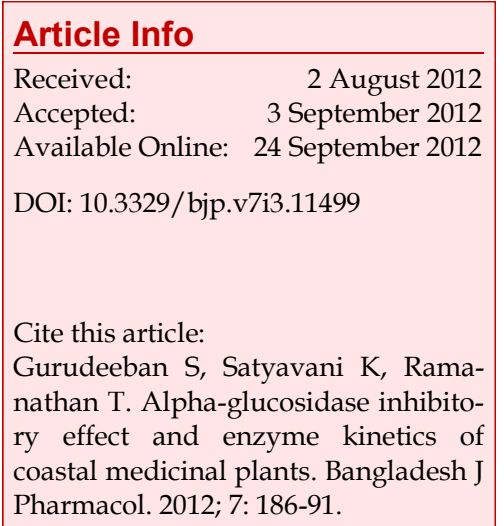

\begin{abstract}
Numerous metabolic disorders and diseases associated with the glucosidase enzyme activity. Therefore, in the present study we evaluated alpha glucosidase inhibitory effect of coastal medicinal plants on Saccharomyces cerevisiae a-glucosidase to control postprandial hyperglycemia. The n-hexane extracts of study plants screened for a-glucosidase inhibitory activity using yeast glucosidase. The enzyme kinetics studied Line weaver burk plot method. Among the ten plants Citrullus colocynthis, Aegle marmelos and Ipomoea pes-caprae exhibited potent a-glucosidase inhibitory activity, $85.9 \pm$ $0.1,72.2 \pm 0.3$ and $67.9 \pm 0.1$ respectively. From the enzyme kinetics assay potent plants contain uncompetitive inhibitors of alpha glucosidase. $C$. colocynthis, A. marmelos and Ipomoea pes-caprae have potential alphaglucosidase inhibitors that can exploited for its used to treat diabetes.
\end{abstract}

\section{Introduction}

About $2.5-7 \%$ of the world's populations diagnosed with leading endocrine disease diabetes mellitus which causes morbidity and mortality (Seghrouchni et al., 2002). By the act of pancreatic a-amylase, starch has hydrolyzed and absorbed as glucose in the small intestine by a-glucosidases, leads to hyperglycemic condition. Moreover, the use of several approaches, aglucosidase inhibitors is one of the alternative therapeutic approaches. Dietary carbohydrates such as maltose and sucrose absorbed by different types of aglucosidases viz. maltase, sucrase, glucoamylase and isomaltase present in the intestine. Thus, inhibition of these enzymes can definitely decrease the postprandial hyperglycemia and could be a key tactic in the managements of diabetes mellitus (Hirsh et al., 1997).

The a-glucosidase inhibitors have isolated from natural sources, such as plants, foodstuffs and microbes (Kumar et al., 2011).

Coastal medicinal plants also engage in recreation to treat diabetes, particularly where most people have limited resources and do not have access to modern treatment (Ramanathan, 2000). The main interest of studies in to medicinal plants with hypoglycemic effect is to understand the metabolic activities of human intestinal tract. Citrullus colocynthis used for constipation, edema, bacterial infections, cancer and diabetes.

The aerial part of C. colocynthis showed antimicrobial and anti-inflammatory, anti-oxidant and local anesthetic effect reported by Gurudeeban et al., (2010). Suaeda monoica, S. maritime and S. nudiflora are traditional medicines for wound healing and hepatitis. The aerial part of this family plant has triterpenoids, sterols which have antiviral activity (Bandaranayake, 2002). Aegle 
marmelos, edible plant which are useful in ophthalmia, deafness, in ammations, catarrh, diabetes and asthmatic complaints, diarrhea, dysentery and stomachalgia, ophthalmia, ulcers, dropsy, cholera and cardio tonic effect like digitalis (Nadkarni, 1976). Sesuvium portulacastrum has essential oils used as a remedy for fever and scurvy (Magwab et al., 2008). Clerodendrum inerme used to treat of skin diseases, veneral infections, elephantiasis and asthma (Anonymous, 2001).

Among these conditions, 10 coastal medicinal plants used to manage diabetes in India namely C. colocynthis, Ipomoea pes-caprae, S. monoica, S. maritime, S. nudiflora, Sesuvium portulacastrum, A. marmelos, Clerodendrum inerme, Ruta graveolens and Casuarina equisetifolia. These medicinal plants are widely explored for their therapeutic potential. However no reports are available on the mechanism of a-glucosidase inhibitory effects. Therefore, the present study aimed to evaluate their effects on reduced glucose utilization effect.

\section{Materials and Methods}

\section{Source of explants}

The aerial parts of the 10 medicinal plants collected from the Southeast coast of India and kept under shade net $(50 \%)$ house environment. The specimen certified by the Herbaria of C. A. S. in Marine Biology, Annamalai University and Botanical Survey of India (BSI) Coimbatore, Tamil Nadu.

\section{Preparation of extract}

The aerial parts of the plants extracted with $n$-hexane using a Soxhlet assembly for 48 hours, filtered and last traces of the solvent evaporated under reduced pressure in a rotary evaporator. The resulting extract filtered through filter paper (Whatman No. 1). The experimental chemicals purchased from Sigma-Aldrich Mumbai.

\section{Assay for a-glucosidase inhibitory activity}

Alpha-glucosidase activity estimated according to the method previously reported by Shibano et al. (1997) with trivial alterations. $50 \mu \mathrm{L}$ of $0.1 \mathrm{M}$ phosphate buffer (with $\mathrm{pH}$ of 7.0), $10 \mu \mathrm{L}$ of test sample and $25 \mu \mathrm{L}$ of aglucosidase solution incubated at $37^{\circ} \mathrm{C}$ for $30 \mathrm{~min}$ and blanks prepared simultaneously. Then the reaction terminated by the addition of $100 \mu \mathrm{L}$ of $0.2 \mathrm{M}$ sodium carbonate solution. The enzymatic hydrolysis of substrate examine by the amount of p-nitrophenol released in the reaction mixture at $410 \mathrm{~nm}$ using microplate reader. Controls conduct in an identical manner replacing the plant extract with methanol and $\beta$-D-Glucose used as positive control. All experiments carried out in triplicates. The inhibition percentage of a-glucosidase assess by the following formula: a-glucosidase $\%=100 \mathrm{X}$ (control-sample)/controlwhereas,

Control $=$ test - blank; Sample $=$ test - blank.

\section{Kinetics of a-glucosidase inhibitor}

To determine the plants extracts inhibition against $S$. cerevisiae a-glucosidase, with increasing concentration of PNPG (4-nitrophenyl a-D-glucopyranoside) used as substrate in the absence and presence of plant extracts at different concentrations. The data determined by Line weaver-Burk plot analysis of the data (Line

\section{Table I}

\section{a-Glucosidase inhibitory effect of coastal medicinal plants (Southeast coast of India)}

\begin{tabular}{|llccc|}
\hline Plant name & Voucher No. & Family & Plant parts used & \% of a-glucosidase inhibition \\
\hline Aegle marmelos & AUCASMB65 & Rutaceae & leaf \& fruit & $72.2 \pm 0.3$ \\
Casuarina equisetifolia & AUCASMB67 & Casuarinaceae & leaf & $24.9 \pm 0.4$ \\
Citrullus colocynthis & AUCASMB66 & & whole part & $85.9 \pm 0.1$ \\
Clerodendrum inerme & AUCASMB33 & Verbenaceae & leaf & $41.0 \pm 0.3$ \\
Ipomoea pes-caprae & AUCASMB68 & Convolvulaceae & whole part & $67.9 \pm 0.1$ \\
Ruta graveolens & AUCASMB69 & Rutaceae & leaf \& fruit & $25.8 \pm 0.2$ \\
Suaeda monoica & AUCASMB19 & Chenopodiaceae & whole part & No activity \\
Suaeda maritime & AUCASMB20 & & & \\
Suaeda nudiflora & AUCASMB21 & & & \\
Sesuvium portulacastrum & AUCASMB22 & Aizoaceae & & \\
\hline
\end{tabular}


Table II

Kinetics effect of $\alpha$-glucosidase inhibition on plant extracts

\begin{tabular}{|ccccccc|}
\hline $\begin{array}{c}\text { Concentration } \\
(\mu \mathrm{g} / \mathrm{mol})\end{array}$ & \multicolumn{2}{c}{ Citrullus colocynthis } & \multicolumn{2}{c|}{ Aegle marmelos } & \multicolumn{2}{c|}{ Ipomoea pes-caprae } \\
\cline { 2 - 7 } & $\mathrm{K}_{\mathrm{m}}(\mathrm{mM})$ & $\mathrm{V}_{\max }\left(\mathrm{mM} / \mathrm{min}^{-1}\right)$ & $\mathrm{K}_{\mathrm{m}}(\mathrm{mM})$ & $\mathrm{V}_{\max }\left(\mathrm{mM} / \mathrm{min}^{-1}\right)$ & $\mathrm{K}_{\mathrm{m}}(\mathrm{mM})$ & $\mathrm{V}_{\max }\left(\mathrm{mM} / \mathrm{min}^{-1}\right)$ \\
0 & 1.226 & 0.883 & 3.900 & 0.334 & 2.633 & 0.243 \\
4 & 1.562 & & 4.329 & 0.365 & 5.675 & 0.250 \\
8 & 0.886 & 0.851 & 2.633 & 0.312 & 4.248 & 0.243 \\
\hline
\end{tabular}

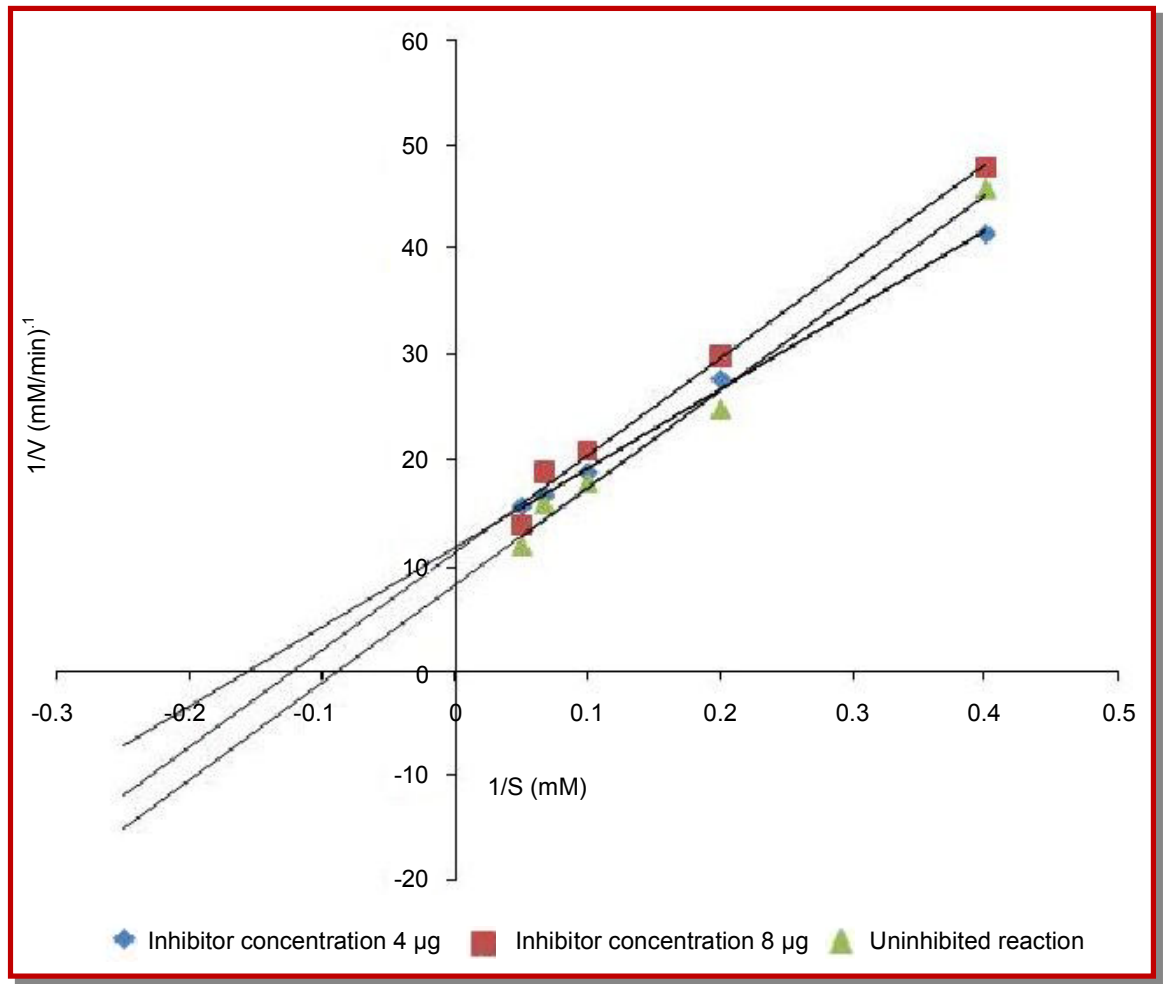

Figure 1 : Lineweaver-Burk plot of $S$. cerevisiae a-glucosidase and PNPG with $4 \mu \mathrm{g} / \mathrm{mL}$ and $8 \mu \mathrm{g} / \mathrm{mL}$ of citrullus colocynthis extract

weaver, 1934), which calculated from the result according to Michaelis-Menten kinetics.

\section{Statistical analysis}

All assays performed at three times with triplicates samples. Values represented as mean \pm Standard deviation.

\section{Results and Discussion}

Coastal plants are most promising source for recent drug development in marine pharmacological research. Earlier reports revealed the basic reason for diabetic mellitus, that the enzyme a-glucosidase participated in biological process like digestion, biosynthesis of glycol- protein and mainly involve in the cleavage of glycosidic bond, as a result increase in blood glucose level leads to chronic hyperglycemia. One of the therapeutic approaches for decreasing postprandial hyperglycemia is to retard absorption of glucose by carbohydrate hydrolyzing enzymes, a-amylase and a-glucosidase inhibition, in the digestive organs (Deshpande et al., 2009). Hence, we evaluated 10 coastal plants to develop such eminent a-glucosidase inhibitors from marine floral resources for reducing wide range of side effects. Among the 10 study plants A. marmelos, C. colocynthis and I. pes-caprae showed moderate a-glucosidase inhibitory activity. Ruta graveolens and Casuarina equisetifolia showed less inhibitory activity and salt marsh plants S. monoica, S. maritime, S. nudiflora and Sesuvium portulacastrum did not posses any inhibition 


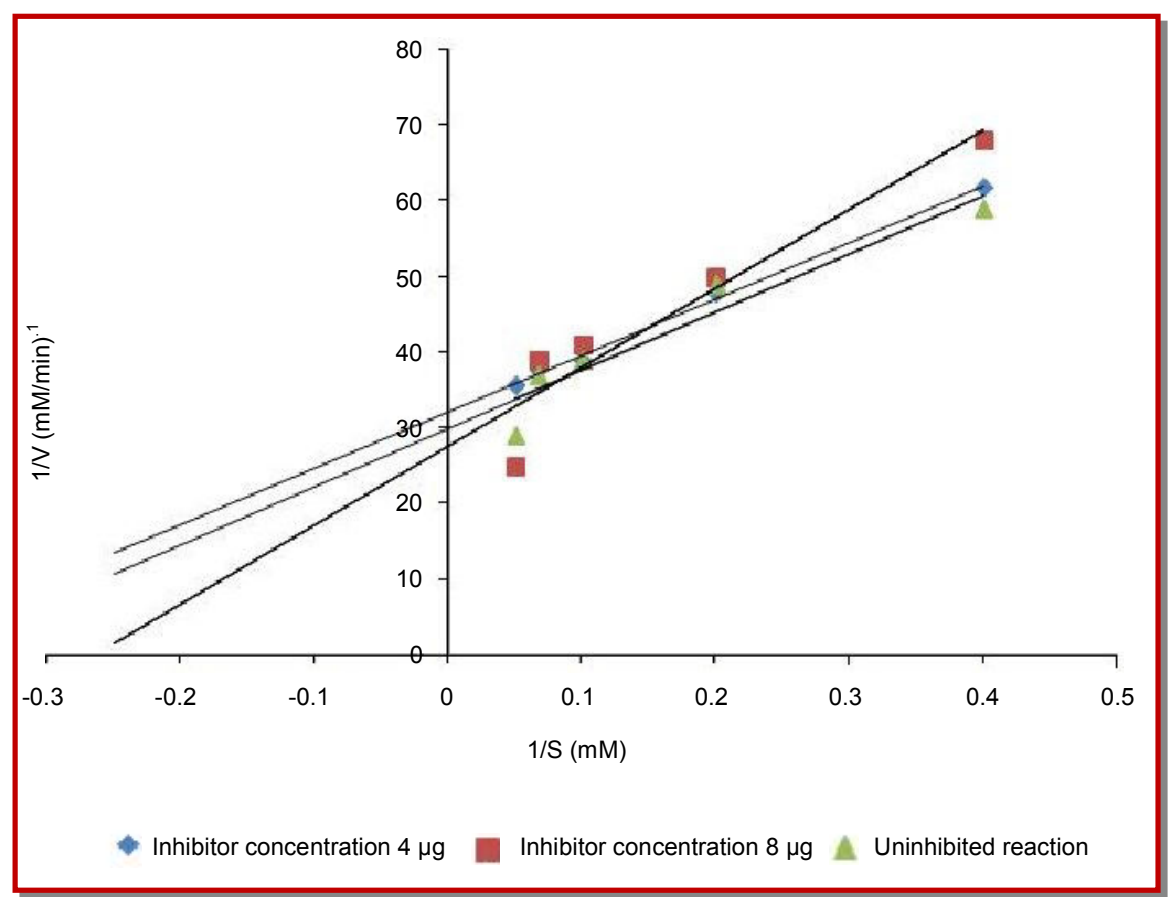

Figure 2 : Lineweaver-Burk plot of $S$. cerevisiae a-glucosidase and PNPG with $4 \mu \mathrm{g} / \mathrm{mL}$ and $8 \mu \mathrm{g} / \mathrm{mL}$ of Aegle marmelos extracts

against S. cerevisiae a-glucosidase. Acarbose used as positive control which showed low a-glucosidase inhibitory potential with IC50 value of $133 \mu \mathrm{g} / \mathrm{mL}$ (Table I).

Earlier studies, most mammalian a-glucosidase inhibitors did not effectively inhibit microbial a-glucosidases (Oki et al., 1999), because plants and mammalian enzymes are maltostructure, it hydrolyze homogeneous substrate whereas bacterial, yeast, and insect enzymes are maltooligosaccharides show higher activity toward heterogeneous substrates such as sucrose and pNPG, and no activity toward homogeneous substrates (Kimura, 2002; Kimura et al., 2004). Our present result exhibits the strong enzymatic inhibitory activity against yeast a- glucosidases shown by three plant extracts ( $A$. marmelos, C. colocynthis and I. pes-caprae) is obviously enhanced than the commercial inhibitor acarbose at low concentration. This will favor that A. marmelos, $C$. colocynthis and I. pes-caprae extracts can decrease blood glucose level.

The inhibition kinetics of A. marmelos, C. colocynthis and I. pes-caprae analyzed by Lineweaver-Burk plot analysis, which indicated that it is a non-competitive inhibitor with respect to PNPG for S. cerevisiae a-glucosidase (Table II). Inhibitor concentration $(\mu \mathrm{g} / \mathrm{mL})$ plotted on the $\mathrm{X}$-axis and $1 / \mathrm{V}(\mathrm{mM} / \mathrm{min})-1$ values obtained from the Lineweaver-Burk plot plotted on the Y-axis. The aerial extract of $C$. colocynthis has uncompetitive inhibitor (s) of alpha-glucosidase (Figure 1) and reduc- tion of Vmax from $1.2 \mathrm{mM} / \mathrm{min}-1$ to $0.8 \mathrm{mM} / \mathrm{min}-1$ and $\mathrm{Km}$ from $1.6 \mathrm{mM}$ to $0.9 \mathrm{mM}$. The leaf and fruit extract of A. marmelos has mixed inhibitors of alpha glucosidase (Figure 2) and there is a reduction in Vmax from 3.7 $\mathrm{mM} / \mathrm{min}-1$ to $3.1 \mathrm{mM} / \mathrm{min}-1$ and $\mathrm{Km}$ from $4.3 \mathrm{mM}$ to $2.6 \mathrm{mM}$. The aerial extract of I. pes-caprae (Figure 3) has uncompetitive inhibitors of alpha-glucosidase and there is reduction of Vmax from $0.3 \mathrm{mM} / \mathrm{min}-1$ to $0.2 \mathrm{mM} /$ min- 1 and the $\mathrm{Km}$ from $5.7 \mathrm{mM}$ to $4.2 \mathrm{mM}$. The commercial alpha-glucosidase inhibitor, acarbose is a competitive inhibitor of the enzyme and it required at higher concentration to reduce the post-prandial glucose level. The uncompetitive inhibitors bind to the enzyme-substrate complex, lowering the $\mathrm{Km}$ and the maximum enzyme activity (Vmax).

\section{Conclusion}

Inhibition of a-glucosidase is one of the therapeutic approaches for preventing post postprandial hyperglycemia. Hence, the explore for a-glucosidase inhibitors in coastal medicinal plants is imperative because these inhibitors could control the postprandial hyperglycemia of diabetic patients.

\section{Acknowledgements}

The authors are gratefully acknowledged to the Director and 


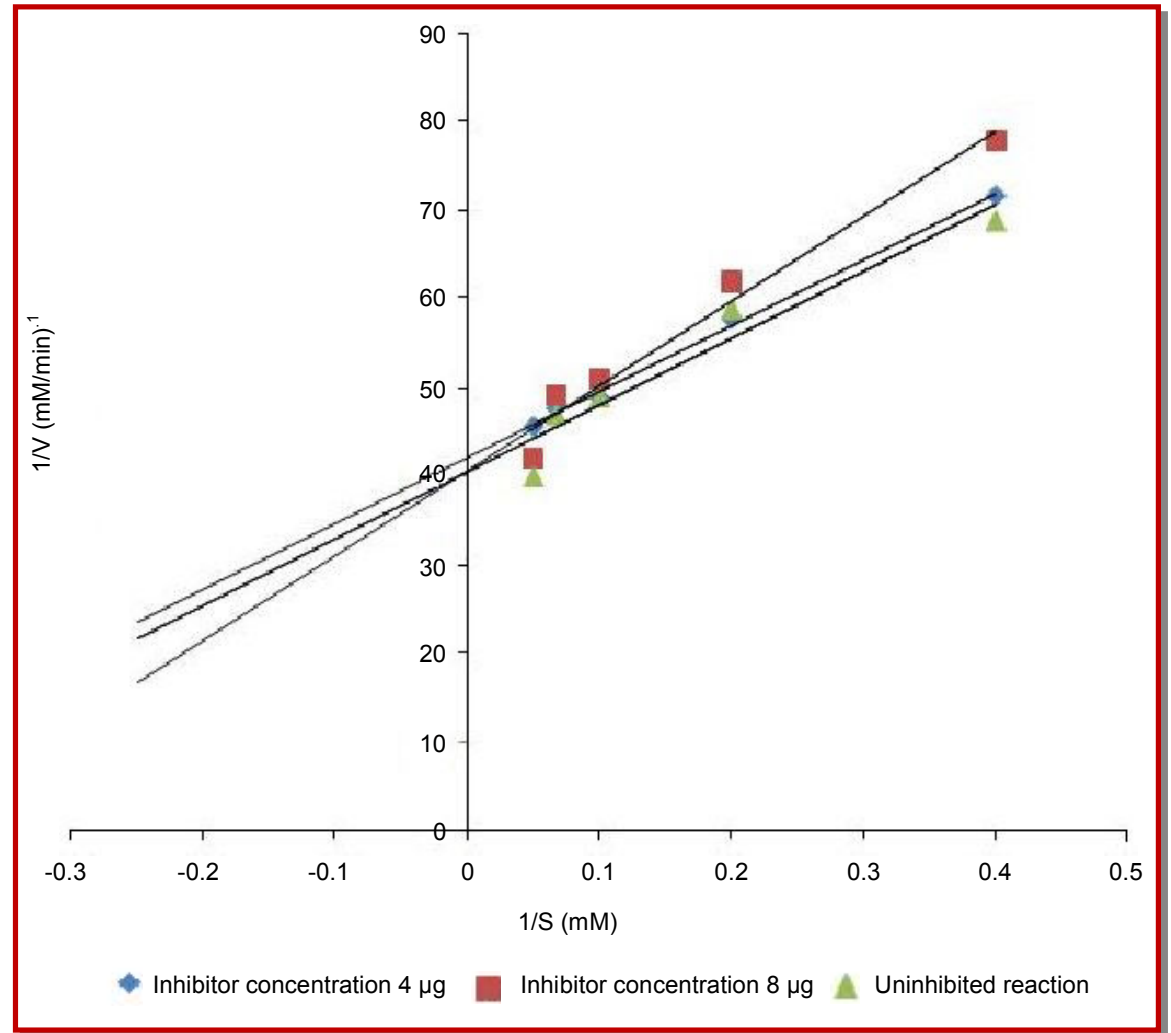

Figure 3 : Lineweaver-Burk plot of $S$. cerevisiae a-glucosidase and PNPG with $4 \mu \mathrm{g} / \mathrm{mL}$ and $8 \mu \mathrm{g} / \mathrm{mL}$ of Ipomoea pes-caprae extracts

Dean, Faculty of Marine Sciences and authorities of Annamalai University, India for providing all support during the study period.

\section{References}

Anonymous I. Wealth of India. National Institute of Science Communication and Council of Scientific and Industrial Research, New Delhi. 2001; 2: 67-68.

Bandaranayake WM. Bioactivities, bioactive compounds and chemical constituents of mangrove plants. Wet Ecol Manag. 2002; 10: 421-452.

Deshpande MC, Venkateswarlu V, Babu RK, Trivedi RK. Design and evaluation of oral bioadhesive controlled release formulations of miglitol, intended for prolonged inhibition of intestinal alpha-glucosidases and enhancement of plasma glycogen like peptide-1 levels. Int J Pharm.2009; 380:16-24.

Gurudeeban S, Satyavani K, Ramanathan T. Bitter apple (Citrullus colocynthis): An overview of chemical composition and biomedical potentials. Asian J Plant Sci. 2010; 9: 394-401.

Hirsh AJ, Yao SY, Young JD, Cheeseman CI. Inhibition of glucose absorption in the rat jejunum: A novel action of alpha-D-glucosidase inhibitors. Gastroenterology 1997; 113: 205-11.
Kimura A. Molecular anatomy of a-glucosidase. Trends Glycosci Glyc. 2000; 12: 373-80.

Kimura K, Lee JH, Lee IS, Lee HS, Park KH, Chiba S, Kim D. Two potent competitive inhibitors discriminating alphaglucosidase family I from family II. Carbohyd Res. 3 2004; 39: $1035-40$

Kumar S, Narwal S, Kumar V, Prakash O. a-glucosidase inhibitors from plants: A natural approach to treat diabetes. Pharmacogn Rev. 2011; 5: 19-29.

Line weaver H, Burk D. The Determination of Enzyme Dissociation Constants. J Am Chem Soc. 1934; .56: 658-66.

Magwab ML, Mazuru G, Nyasha G, Godfred H. Chemical composition and biological activities of essential oil from the leaves of Sesuvium portulacastrum. J Ethnopharmacol. 2006; 103: 85-89.

Nadkarni AK. Indian Materia Medica. 3rd ed. Mumbai, Popular Press, 1976, p 8.

Oki T, Matsui T, Osajima Y. Inhibitory effect of a-glucosidase inhibitors varies according to its origin. J Agric Food Chem. 1999; 47: 550-53.

Ramanathan T. Studies on medicinal plants of Parangipettai Coast (Southeast coast of India). Ph.D. Thesis, Annamalai University, India. 2002, p 81. 
Seghrouchni I, Dral J, Bannier E. Oxidative stress parameters in type I, type II and insulin treated type II diabetes mellitus: Insulin treatment efficiency. Clin Chem Acta. 2002; 321: 89-96.

Shibano M, Kitagawa S, Nakamura S, Akazawa N, Kusano G.
Studies on the constituents of Broussonetia species. II. Six new pyrrolidine alkaloids, broussonetine A, B, E, F and broussonetinine A and B, as inhibitors of glycosidases from Broussonetia kazinoki Sieb. Chem Pharm Bull. 1997; 45: 70005 . 